\title{
The accuracy of polyp assessment during colonoscopy in FIT-screening is not acceptable on a routine basis ${ }^{1}$
}

\author{
Authors \\ Institutions \\ Inge Stegeman ${ }^{1}$, Sascha van Doorn ${ }^{2}$, Rosalie Mallant-Hent ${ }^{3}$, Manon van der Vlugt ${ }^{2}$, Marco Mundt ${ }^{3}$, Paul Fockens ${ }^{2}$, \\ Patrick Bossuyt ${ }^{1}$, Evelien Dekker ${ }^{2}$ \\ ${ }^{1}$ Department of Clinical Epidemiology, Biostatistics and Bioinformatics, Academic Medical Center, Amsterdam, Netherlands \\ ${ }^{2}$ Department of Gastroenterology and Hepatology, Academic Medical Center, Amsterdam, Netherlands \\ 3 Department of Gastroenterology and Hepatology, Flevoziekenhuis Almere, Netherlands
}

submitted 25. May 2014 accepted after revision 22. April 2014

\section{Bibliography}

Dol http://dx.doi.org/ 10.1055/s-0034-1377173 Published online: 23.6.2014 Endoscopy International Open 2014; 02: E127-E132

(c) Georg Thieme Verlag KG Stuttgart . New York E-ISSN 2196-9736

\section{Corresponding author} Inge Stegeman Academic Medical Center Clinical Epidemiology, Biostatistics and Bioinformatics Meibergdreef 91105 AZ Amsterdam, Utrecht 3522BD Netherlands

Fax: 0031612435610 i.stegeman@umcutrecht.nl
Background: During colonoscopy, correct assessment of polyps is important. Recognition of early carcinomas is needed for tailor-made treatment and avoidance of unnecessary complications. Moreover, accurate diagnosis of diminutive lesions could result in a safe resect and discard strategy. We assessed the accuracy of polyp assessment by general endoscopists without specific training or experience in image-enhanced endoscopy during routine colonoscopies within a fecal immunochemical test (FIT)-based screening program.

Methods: Data were collected in the third round of a FIT-based colorectal cancer screening pilot program. Patients diagnosed as FIT-positive (318) underwent colonoscopy using Olympus (160 and 180 series) endoscopes without magnification or routine use of (virtual) chromoendoscopy. Endoscopists received no special training. They made an on-site evaluation and classified detected polyps as hyperplastic, adenoma, carcinoma. Samples of resected lesions were sent for histopathology. Sensitivity and specificity were

\section{Introduction \\ $\nabla$}

Screening for colorectal cancer, one of the most common causes of cancer-related mortality [1], has been shown to decrease colorectal cancer mortality rates. In colorectal cancer screening, histopathology is the reference standard for the classification of polyps detected during colonoscopy. There are several reasons why it is recommended that endoscopists predict the histopathology of the colonic lesions detected. First, accurate recognition of early carcinomas is essential in the decisions related to follow-up treatment.

${ }^{1}$ Funding: The study was supported by a grant from The Netherlands Organization for Health Research and Development of the Dutch Ministry of Health (ZonMW 12010095420). calculated. We differentiated for fellows and consultants.

Results: In the 318 patients with a positive FITscreening result, 683 lesions were detected; 564 lesions were included in the analyses. The pathologist classified these lesions as 141 hyperplastic polyps, 349 adenomas, 16 carcinomas, and 58 other. Sensitivity for diagnosis of adenomas was $88 \%$ (95\%CI 84-91); specificity 49\% (95\%CI 42 55). Of the 16 colorectal carcinomas, endoscopists diagnosed four incorrectly (sensitivity 75\% [95\% CI 44-89]; specificity 99\% [95\%CI 98-100]), including three stage I cancers and one stage III cancer. There were no differences in accuracy of diagnosis that related to different sizes of lesions or the experience of the endoscopist.

Conclusion: In a routine FIT-based screening setting and without specific training or routine use of (digital) chromoendoscopy, endoscopic prediction of the histopathology of colonic lesions is inaccurate when the procedure is performed by general endoscopists.

For some early carcinomas, endoscopic resection is feasible while others should be primarily referred for surgery, avoiding a complication risk of polypectomy. Moreover, every suspicious lesion should be marked with a tattoo to secure future localization [1-4]. Second, colonoscopy would become more efficient and cost-effective if the endoscopist was able to differentiate lesions based on the endoscopic image only, and if only a rather limited number of polyps had to be sent for pathological examination. Discarding lesions without histopathologic evaluation would reduce costs and time required for final diagnosis and determining a surveillance interval. However, this would only acceptable if lesions of interest were correctly identified during colonoscopy and if cancers were not missed. The landmark "DISCARD-trial" and several subsequent studies dem- 


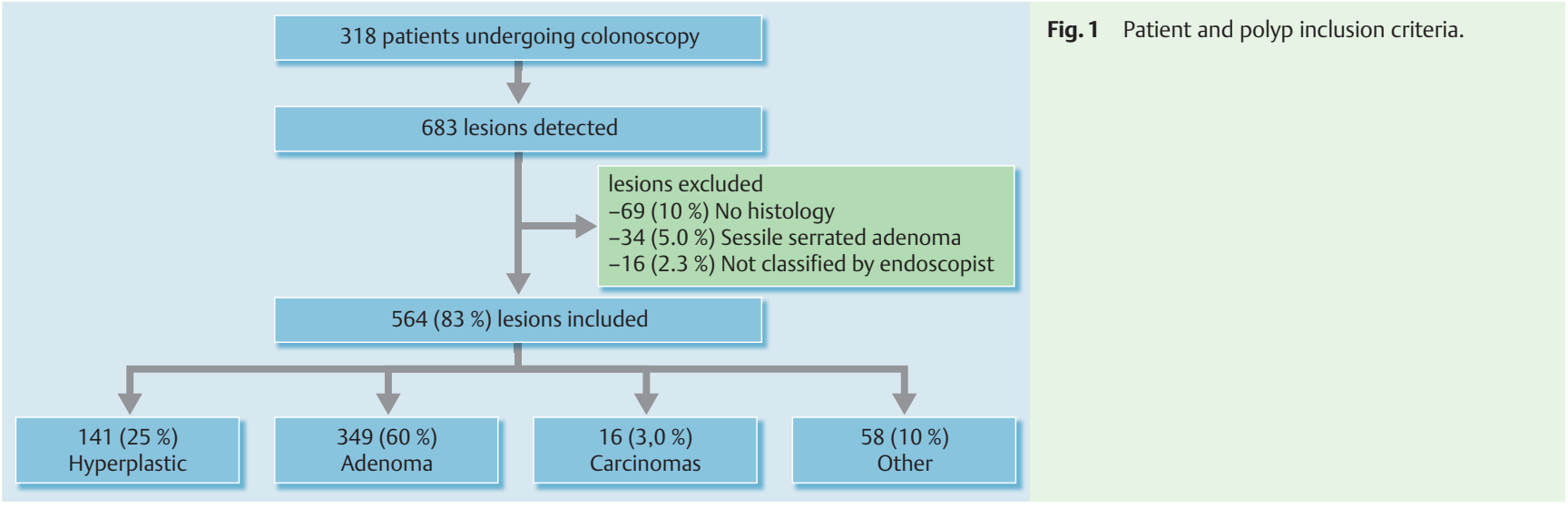

onstrated that expert endoscopists reach a negative predictive value of $90 \%$ or more for diminutive adenomas and this was regarded as an appropriate threshold for discarding the use of pathological assessment in diagnosing these lesions [2,5]. However, these studies were conducted in an expert setting with systematic use of advanced imaging techniques. A Dutch study in a non-academic setting showed optical diagnosis of colorectal lesions with narrow band imaging (NBI) is suboptimal [6]. Third, in routine colonoscopy, resected polyps are obtained for histopathologic assessment. In some cases, however, the endoscopist is unable to obtain all polyps for histopathologic assessment; therefore, surveillance intervals must be determined by the predicted histopathology.

In the routine daily setting of the third round of a FIT-based screening pilot program, we retrospectively evaluated the ability of endoscopists to predict the histopathology of colorectal lesions with conventional white light colonoscopy. In addition, we compared the accuracy of diagnosis of different sized lesions: diminutive, small, and large, and compared the accuracy of the diagnoses of gastroenterology consultants and fellows.

\section{Methods}

$\nabla$

Data were collected during colonoscopies performed in the third round of a pilot program of FIT-based screening for CRC in Amsterdam, the Netherlands. The methods and results for the separate screening rounds have been reported in detail elsewhere [2, 4]. FITs and the reagents required for laboratory assessment were provided by Eiken Chemical Company, LTD, Japan.

\section{Population and design \\ $\nabla$}

Asymptomatic individuals between 50 and 75 years were invited to participate in FIT-based screening. Institutionalized people were excluded from participation. Participants who had tested negative in the first or second round of assessments were invited to participate again. More information about the design and procedures for invitations have been described elsewhere $[2,6]$.

\section{Colonoscopy and pathology}

All participants with a positive FIT-screening test were invited for a consultation at one of the two screening centers between July and December 2011. During this consultation, the implications of the positive test were described to the participant. If no contraindications were present, a colonoscopy was advised and the procedure was discussed with the participant.

All colonoscopies were performed using Olympus (160 and 180 series) endoscopes without standard use of NBI, However, NBI or chromoendoscopy were used upon the discretion of the endoscopist. Twelve endoscopists were gastrointestinal tract consultants and eleven were fellows.

Histopathologists were blinded for the outcome of the endoscopic assessment. Data on location, size, macroscopic aspect (endoscopic diagnosis; eg., hyperplastic polyp, adenoma, carcinoma, or other), morphology, procedure for removal, and endoscopic assessment of radical resection of each consecutive patient were recorded for all lesions detected during colonoscopy. Lesions were evaluated according to the Vienna criteria by an experienced gastrointestinal pathologist, who was blinded to the endoscopic assessment $[2-4,7]$. Lesions were classified as an adenocarcinoma, an adenoma (tubular, tubulovillous, villous), a hyperplastic polyp, a sessile serrated adenoma, a traditional serrated adenoma, or as miscellaneous. Dysplasia was defined as either low-grade or high-grade.

\section{Statistics \\ $\nabla$}

Sensitivity and specificity estimates were calculated by comparing the evaluation by the endoscopist with the histopathology findings, which was used as the clinical reference standard. Lesions were categorized as hyperplastic, adenoma, carcinoma or other (eg., pseudo polyps, normal polyp-like mucosa, inverted diverticulosis). We statistically assessed adenomas and carcinomas versus other lesions. Lesions were excluded if no histology was available or if the lesion was a sessile serrated adenoma/ polyp or traditional serrated adenoma because these are difficult to recognize and were not included in the endoscopist's options on the Clinical Research Form ( Fig. 1). We did not collect data on reproducibility.

We analyzed separately diminutive ( $<6 \mathrm{~mm})$, small $(6-9 \mathrm{~mm})$, and large $(\geq 10 \mathrm{~mm})$ lesions and diagnoses by the fellows and consultants. Chi square test statistics were used to compare the 
Table 1 Characteristics of included lesions.

\begin{tabular}{|lrrrr|}
\hline & $\begin{array}{l}\text { All } \\
(\mathbf{5 6 4})\end{array}$ & $\begin{array}{l}\text { Hyperplastic } \\
(\mathbf{N}=\mathbf{1 4 1})\end{array}$ & $\begin{array}{l}\text { Adenoma } \\
(\mathbf{N = 3 4 9 )}\end{array}$ & $\begin{array}{l}\text { Carcinoma } \\
(\mathbf{N}=\mathbf{1 6})\end{array}$ \\
\hline Size & & & & \\
$\quad<6 \mathrm{~mm}$ & 353 & 117 & 194 & 0 \\
$6-9 \mathrm{~mm}$ & 108 & 20 & 83 & 0 \\
$\geq 1 \mathrm{~cm}$ & 94 & 3 & 68 & 16 \\
$\quad$ Missing & 9 & 1 & 4 & \\
\hline Location & & & & \\
$\quad$ Distal & 307 & 104 & 161 & 10 \\
$\quad$ Proximal & 205 & 28 & 145 & 6 \\
$\quad$ Missing & 52 & 9 & 43 & \\
\hline
\end{tabular}

proportions in subgroups. Statistical analyses were performed with SPSS 19.0.

\section{Results}

In the third FIT-screening round, 318 patients with a positive FIT screen underwent colonoscopy; their mean age was 62.3 (SD $6.8) ; 176$ (55\%) were men. Mean number of polyps per patient was 2.6 (SD 1.75). The colonoscopies were performed by 23 endoscopists in two hospitals; eight endoscopists performed 260 colonoscopies (74\%). Two-hundred and four screening participants $(64 \%)$ had at least one lesion detected during colonoscopy. In all, 683 lesions were detected; 564 (83\%) of these were included in the analyses ( $\bullet$ Fig. 1 ).

\section{All lesions}

The pathologists classified the 564 lesions as: 141 hyperplastic polyps, 349 adenomas, 16 carcinomas, and 58 other lesions ( Fig. 1 and $\square$ Table 1 ). Table 2 shows the sensitivity, specificity, and positive and negative predictive valued (PPV and NPV) for polyp assessment for diagnosis of adenoma and carcinoma.

For adenomas, endoscopic assessment was correct for 307 of 349 lesions ( $88 \%)$. Of the 42 lesions that were incorrectly diagnosed by the endoscopist as an adenoma, histopathology revealed 40 (11\%) hyperplastic polyps and two cancers $(0.6 \%)$. The sensitivity

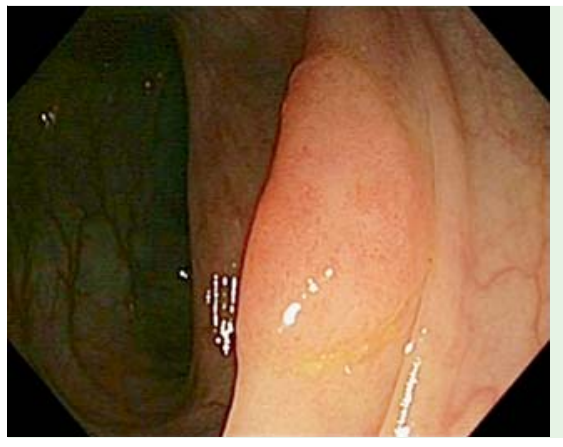

Fig. 2 Flat polyp $(8 \mathrm{~mm})$ in the transverse colon, which was, after submucosal lifting with normal saline, removed with snare polypectomy. Histopathology predicted a hyperplastic polyp, however, it was identified as a tubular adenoma with low-grade dysplasia.

of the endoscopist for adenomas was $88 \%$ (95\%CI 84-91) and specificity was $49 \%$ (95\%CI $42-55)$. $\bullet$ Fig. 2 shows a hyperplastic polyp that was assessed by the endoscopist as an adenoma.

Endoscopic diagnosis was correct in 12 of the 16 cancers (75\%). All four incorrectly diagnosed cancers were assessed by the endoscopist as adenoma and were $10-15 \mathrm{~mm}$ in diameter. None of these carcinomas were marked with a tattoo.

We classified the cancers using the American Joint Committee on Cancer stages ( Table 3 ). Seven cancers were stage I and four of these were correctly identified as carcinomas by the endoscopist. All three incorrectly classified carcinomas were assessed as an adenoma. Fig. 3 shows one of these lesions. Two of the misdiagnosed carcinomas were sessile lesions and one was pedunculated. Two carcinomas were classified as stage II and both were correctly identified by the endoscopist. Seven carcinomas were classified as stage III; six were correctly identified and one was assessed as a sessile adenoma. Table 4 and $\bullet$ Table 5 show the sensitivity and specificity for fellows and consultants for diagnosis of adenomas and carcinomas, respectively. There were no significant differences in polyp assessment between the two groups of endoscopists.

\section{Size}

- Table 6 and Table 7 show the endoscopic prediction subdivided for diminutive, small, and large lesions for adenomas and carcinomas, respectively. Of 564 lesions, 351 (62\%) were

Table 2 Sensitivity and specificity for adenomas and carcinomas.

\begin{tabular}{|c|c|c|c|c|c|}
\hline & All lesions ( $N=564)$ & & & PPV & NPV \\
\hline \multirow{2}{*}{ Endoscopist } & \multicolumn{3}{|l|}{ Histopathology } & & \\
\hline & Adenomatous & Non-adenomatous & Total & & \\
\hline Adenomatous & $307(88 \%)$ & $110(51 \%)$ & $417(74 \%)$ & $74 \%$ & $26 \%$ \\
\hline Non-adenomatous & $42(12 \%)$ & $105(49 \%)$ & $147(26 \%)$ & & \\
\hline Total & $349(62 \%)^{*}$ & $215(38 \%)$ & 564 & & \\
\hline Sensitivity (95\%Cl) & $88 \%(84-91)$ & & & & \\
\hline \multirow[t]{3}{*}{ Specificity $(95 \% \mathrm{Cl})$} & $49 \%(42-55)$ & & & & \\
\hline & \multicolumn{3}{|l|}{ Carcinoma } & & \\
\hline & Carcinoma & Non-carcinoma & Total & & \\
\hline Carcinoma & $12(75 \%)$ & $3(0.5 \%)$ & $15(2.7 \%)$ & $2.7 \%$ & $97 \%$ \\
\hline Non-carcinoma & $4(25 \%)$ & $545(99 \%)$ & 549 (97\%) & & \\
\hline Total & $16(2.8 \%)$ & $548(97 \%)$ & 564 & & \\
\hline Sensitivity $(95 \% \mathrm{Cl})$ & $75 \%(44-89)$ & & & & \\
\hline Specificity $(95 \% \mathrm{CI})$ & $99 \%(98-100)$ & & & & \\
\hline
\end{tabular}

* $62 \%$ of all adenomatous lesions as assessed by the histopathologist. 
Table 3 Classification of Carcinomas $(\mathrm{N}=16)$.

\begin{tabular}{|llcc|}
\hline & Endoscopist & \\
\hline Histopathology & Adenoma & Carcinoma & Total \\
\hline Stage $\left({ }^{*}\right)\left({ }^{* *}\right)$ & & & \\
\hline I & 3 & 4 & 7 \\
\hline II & 0 & 2 & 2 \\
\hline III & 1 & 6 & 7 \\
\hline Total & 4 & 12 & 16 \\
\hline
\end{tabular}

* All carcinomas were $\geq 10 \mathrm{~mm}$.

** TNM classification and staging, $7^{\text {th }}$ edition ${ }^{9}$

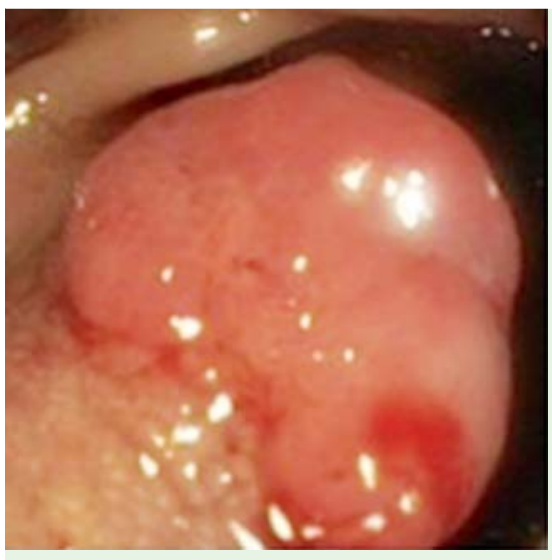

Fig. 3 Sessile polyp $(10 \mathrm{~mm})$ localized in the distal sigmoid, removed in toto with snare polypectomy after lifting with normal saline. Histopathology predicted an adenomatous polyp; no tattoo was placed; however, it was identified as an adenocarcinoma with submucosal invasion. Additional laparoscopic low anterior resection was performed. The resection specimen revealed no residual tumor, but one local positive lymph node. The colorectal carcinoma was classified as stage III.

scored as diminutive, 108 (19\%) as small, and 95 (17\%) as large; in $10(1.8 \%)$ lesions the size was not recorded. All 16 carcinomas were $10 \mathrm{~mm}$ or larger. There were no significant differences in the endoscopist's accuracy of polyp assessment between diminutive, small, and large lesions.
Negative predictive value for diminutive lesions

Negative predictive value for diminutive adenomas was $69 \%$ $(60-77)$. Because no diminutive carcinomas were detected and no polyps were classified as carcinomas, the NPV for diminutive carcinomas was not calculated.

\section{Discussion \\ $\nabla$}

Our study evaluated the accuracy of endoscopists in their assessment of polyps from colonic lesions detected during routine colonoscopy among FIT-positive participants in a third round of screening. Our study suggests endoscopic prediction of histopathology of polyps and early cancer is suboptimal in daily practice of a FIT-based screening program using routine white light colonoscopy.

Some limitations of our study should be discussed. It has been shown that training improves accuracy for correct prediction of histopathology $[1,5,8,9]$. All endoscopists were experienced in performing routine colonoscopies, however, they did not receive any specific training for assessment of polyps from colorectal lesions. However, our intention was to evaluate polyp assessment of endoscopists in a routine, daily setting. In that setting, endoscopists used Olympus 160 and 180 endoscopes. They were allowed to use NBI or chromoendoscopy at their discretion, but this was not usually done. Literature demonstrates that advanced colonoscopic imaging methods like non-magnified/magnified NBI or chromoendoscopy improve accuracy of optical diagnosis [10 -14] Finally, we did not evaluate the level of confidence of the endoscopists in predicting polyp histopathology in diminutive lesions only, as was done previously in the DISCARD-study $[2,5,15]$.

To our knowledge this is the first study to report on endoscopic assessment of polyps during colonoscopies in a FIT-based screening setting. In early 2014, a nationwide FIT-based screening program was implemented in the Netherlands. This will increase the demand on colonoscopic capacity, making cost- and time-effectiveness more important. For routine assessment of basic quality measures in the screening program, an accreditation and auditing system for endoscopists and endoscopic units was established in the UK and is now established in the Netherlands [1,6,

Table 4 Sensitivity and specificity for adenomas for consultants and fellows.

\begin{tabular}{|c|c|c|c|c|c|}
\hline & Consultant $(\mathrm{N}=297)$ & & & PPV & NPV \\
\hline \multirow[t]{2}{*}{ Consultant } & Histopathology & & & & \\
\hline & Adenomatous & Non-adenomatous & Total & & \\
\hline Adenomatous & $166(88 \%)$ & $66(61 \%)$ & $232(78 \%)$ & $78 \%$ & $22 \%$ \\
\hline Non-adenomatous & $22(12 \%)$ & $43(39 \%)$ & $65(22 \%)$ & & \\
\hline Total & $188(63 \%)$ & $109(37 \%)$ & 297 & & \\
\hline Sensitivity $(95 \% \mathrm{Cl})$ & $89 \%(83-93)$ & & & & \\
\hline \multirow[t]{2}{*}{ Specificity (95\%Cl) } & $39 \%(31-50)$ & & & & \\
\hline & Fellows $(N=259)$ & & & & \\
\hline \multirow[t]{2}{*}{ Fellow } & Histopathology & & & & \\
\hline & Adenomatous & Non-adenomatous & Total & & \\
\hline Adenomatous & $134(86 \%)$ & $45(43 \%)$ & $179(69 \%)$ & $69 \%$ & $31 \%$ \\
\hline Non-adenomatous & $21(14 \%)$ & $59(57 \%)$ & $80(31 \%)$ & & \\
\hline Total & $155(60 \%)$ & $104(40 \%)$ & 259 & & \\
\hline Sensitivity $(95 \% \mathrm{Cl})$ & $86 \%(80-91)$ & & & & \\
\hline Specificity $(95 \% \mathrm{Cl})$ & $57 \%(47-66)$ & & & & \\
\hline
\end{tabular}


Table 5 Sensitivity and specificity for carcinomas for consultants and fellows.

\begin{tabular}{|c|c|c|c|}
\hline \multirow{3}{*}{ Consultant } & \multicolumn{3}{|c|}{ Consultant $(\mathrm{N}=297)$} \\
\hline & \multicolumn{3}{|l|}{ Histopathology } \\
\hline & Carcinoma & Non-carcinoma & Total \\
\hline Carcinoma & $6(67 \%)$ & $0(0.0 \%)$ & $6(2.0 \%)$ \\
\hline Non-carcinoma & $3(33 \%)$ & $288(100 \%)$ & $291(98 \%)$ \\
\hline Total & $9(3.0 \%)$ & $288(97 \%)$ & 297 \\
\hline Sensitivity $(95 \% \mathrm{CI})$ & $67 \%(35-91)$ & & \\
\hline \multirow[t]{2}{*}{ Specificity $(95 \% \mathrm{Cl})$} & $100 \%(98-100)$ & & \\
\hline & Fellows $(N=259)$ & & \\
\hline \multirow[t]{2}{*}{ Consultant } & Histopathology & & \\
\hline & Carcinoma & Non-carcinoma & Total \\
\hline Carcinoma & $4(57 \%)$ & $3(1.1 \%)$ & $7(2.7 \%)$ \\
\hline Non-carcinoma & $3(43 \%)$ & 249 (99\%) & $252(97 \%)$ \\
\hline Total & $7(2.7 \%)$ & $252(97 \%)$ & 259 \\
\hline Sensitivity $(95 \% \mathrm{Cl})$ & $57 \%(20-88)$ & & \\
\hline Specificity (95\%Cl) & $99 \%(96-100)$ & & \\
\hline
\end{tabular}

16. Contrary to the outcomes of the DISCARD trial $[2,4,15,17]$, which showed that histopathology could be omitted in a dedicated setting and with the use of NBI, our results show that consideration of histopathology in a setting of FIT-based screening and daily practice should not be omitted when using white light endoscopy only.

If endoscopists were to meet the PIVI-criteria of the American Society of Gastrointestinal Endoscopy, histopathologic assessment of diminutive and, perhaps, small polyps, could be omitted while leaving rectosigmoidal hyperplastic polyps in situ $[1,2,8]$. However, the correct assessment of early carcinomas is important. These lesions are more prevalent in a FIT-positive population. The tailor-made decision to perform endoscopic resection or primary surgical treatment depends on correct endoscopic

Table 6 Sensitivity and specificity for diminutive, smallv and large adenomas.

\begin{tabular}{|c|c|c|c|}
\hline & \multicolumn{3}{|c|}{$<6 \mathrm{~mm}(\mathrm{~N}=351)$} \\
\hline & Adenomatous & Non-adenomatous & Total \\
\hline Adenomatous & $156(80 \%)$ & $73(46 \%)$ & $229(65 \%)$ \\
\hline Non-adenomatous & $38(20 \%)$ & $84(54 \%)$ & $122(35 \%)$ \\
\hline Total & $194(55 \%)$ & $157(45 \%)$ & 351 \\
\hline Sensitivity (95\%Cl) & $80 \%(74-86)$ & & \\
\hline \multirow[t]{3}{*}{ Specificity $(95 \% \mathrm{Cl})$} & $54 \%(45-61)$ & & \\
\hline & \multicolumn{3}{|c|}{$6-9 \mathrm{~mm}(\mathrm{~N}=108)$} \\
\hline & Adenomatous & Non-adenomatous & Total \\
\hline Adenomatous & $82(99 \%)$ & $20(80 \%)$ & $102(94 \%)$ \\
\hline Non-adenomatous & $1(1.0 \%)$ & $5(20 \%)$ & $6(6.0 \%)$ \\
\hline Total & $83(77 \%)$ & $25(23 \%)$ & 108 \\
\hline Sensitivity $(95 \% \mathrm{Cl})$ & $99(93-100)$ & & \\
\hline \multirow[t]{3}{*}{ Specificity $(95 \% \mathrm{Cl})$} & $20(5.3-37)$ & & \\
\hline & $\geq 1 \mathrm{~cm}(\mathrm{~N}=95)$ & & \\
\hline & Adenomatous & Non-adenomatous & Total \\
\hline Adenomatous & $65(96 \%)$ & $13(50 \%)$ & $78(81 \%)$ \\
\hline Non-adenomatous & $3(4.0 \%)$ & $13(50 \%)$ & $17(19 \%)$ \\
\hline Total & $68(72 \%)$ & $26(27 \%)$ & 95 \\
\hline Sensitivity (95\%CI) & $96(87-99)$ & & \\
\hline Specificity $(95 \% \mathrm{Cl})$ & $50(30-70)$ & & \\
\hline
\end{tabular}

assessment of the lesion. Endoscopic resection of a lesion that appears to be invasive in the submucosa can lead to an unnecessary risk of bleeding, perforation, or tumor spread $[2-4,7]$. Our study shows that these lesions are inadequately assessed in routine practice as only four (57\%) of seven early (T1) carcinomas were correctly identified by the endoscopists. Moreover, one stage III carcinoma was misdiagnosed. All incorrectly identified carcinomas were assessed as adenomas and endoscopically resected. In addition, the endoscopist did not place a tattoo to ensure accurate margins for the surgical resection were visible during surgery.

Remarkably, there was no significant difference in accuracy between fellows and consultants, indicating that experience in performing colonoscopies alone is not the key to accurate polyp assessment. Studies have shown that specific training in optical diagnosis increases diagnostic accuracy $[2,5,15]$. It is possible that a training program would enable Dutch endoscopists to meet these criteria. However, for safe assessment and subsequent optimal treatment of carcinomas, optical diagnostic sensitivity must be high and in our study sensitivity for optical detection of carcinomas was disappointing at $75 \%$. The effect of a training program on the endoscopist's recognition of early cancers is not known and should be determined. In addition to improved training of endoscopists, the assessment of polyps could also be improved by upgrading endoscopic technology to high-definition processors, endoscopes, and video-screens. Routine use of image enhancement techniques like chromoendoscopy, NBI, flexible spectral imaging color enhancement, or iScan and standardized classifications like the NBI International Colorectal Endoscopic classification could also improve accuracy of polyp assessment $[18,19]$.

In conclusion, in a Dutch routine practice setting and screening without specific training or use of (digital) chromoendoscopy, endoscopic prediction of the histopathology of colonic lesions is inaccurate and one in four cancers is misdiagnosed as an adeno-

Table 7 Sensitivity and specificity for diminutive, small, and large carcinomas.

\begin{tabular}{|c|c|c|c|}
\hline & \multicolumn{3}{|c|}{$<6 \mathrm{~mm}(\mathrm{~N}=351)$} \\
\hline & Carcinoma & Non-carcinoma & Total \\
\hline Carcinoma & $0(0.0 \%)$ & $0(0.0 \%)$ & $0(0.0 \%)$ \\
\hline Non-carcinoma & $0(0.0 \%)$ & $351(100 \%)$ & $351(100 \%)$ \\
\hline Total & $0(0.0 \%)$ & $351(100 \%)$ & 351 \\
\hline Sensitivity ( $95 \% \mathrm{Cl})$ & NA & & \\
\hline \multirow[t]{3}{*}{ Specificity ( $95 \% \mathrm{Cl})$} & NA & & \\
\hline & \multicolumn{3}{|c|}{$6-9 \mathrm{~mm}(\mathrm{~N}=108)$} \\
\hline & Carcinoma & Non-carcinoma & Total \\
\hline Carcinoma & $0(0.0 \%)$ & $1(0.9 \%)$ & 107 (99\%) \\
\hline Non-carcinoma & $0(0.0 \%)$ & 107 (99\%) & $1(0.9 \%)$ \\
\hline Total & $0(0.0 \%)$ & $108(100 \%)$ & 108 \\
\hline Sensitivity $(95 \% \mathrm{Cl})$ & $0(0-0)$ & & \\
\hline \multirow[t]{3}{*}{ Specificity $(95 \% \mathrm{Cl})$} & $99(94-100)$ & & \\
\hline & \multicolumn{3}{|c|}{$\geq 1 \mathrm{~cm}(\mathrm{~N}=95)$} \\
\hline & Carcinoma & Non-carcinoma & Total \\
\hline Carcinoma & $12(75 \%)$ & $2(2.5 \%)$ & $14(15 \%)$ \\
\hline Non-carcinoma & $4(25 \%)$ & $77(97 \%)$ & $81(85 \%)$ \\
\hline Total & $16(17 \%)$ & $79(83 \%)$ & 95 \\
\hline Sensitivity ( $95 \% \mathrm{Cl})$ & $75(44-91)$ & & \\
\hline Specificity $(95 \% \mathrm{Cl})$ & $50(30-70)$ & & \\
\hline
\end{tabular}


ma. The literature reveals that a specific training program could increase the accuracy of polyp assessment by endoscopists. We find that a training program could help to increase accuracy in daily colonoscopic practice.

\section{Abbreviations \\ $\nabla$ \\ CRC colorectal cancer \\ FIT fecal immunochemical test \\ NBI narrow band imaging \\ NPV negative predictive value \\ PPV positive predictive value}

\section{Competing interests: None.}

\section{References}

1 Ferlay J, Parkin DM, Steliarova-Foucher E. Estimates of cancer incidence and mortality in Europe in 2008. Eur J Cancer 2010; 46: 765-781

2 Stegeman I, de Wijkerslooth TR, Mallant-Hent RC et al. Implementation of population screening for colorectal cancer by repeated Fecal Immunochemical Test (FIT): third round. BMC Gastroenterol 2012; 12: 73

3 Zafar A, Mustafa M, Chapman M. Colorectal polyps: when should we tattoo? Surgical Endoscopy 2012; 26: 3264 - 3266

4 Denters MJ, Deutekom M, Fockens P et al. Implementation of population screening for colorectal cancer by repeated fecal occult blood test in the Netherlands. BMC Gastroenterol 2009; 9: 28

5 Ignjatovic A, Thomas-Gibson S, East JE et al. Development and validation of a training module on the use of narrow-band imaging in differentiation of small adenomas from hyperplastic colorectal polyps. Gastrointestinal Endoscopy 2011; 73: 128-133

6 Kuiper T, Marsman WA, Jansen JM et al. Accuracy for optical diagnosis of small colorectal polyps in nonacademic settings. Clin Gastroenterol Hepatol 2012; 10: 1016-1020

7 Schlemper RJ, Riddell RH, Kato Y et al. The Vienna classification of gastrointestinal epithelial neoplasia. Gut 2000; 47: 251-255

8 Rex DK, Kahi C, O'Brien M et al. The American Society for Gastrointestinal Endoscopy PIVI (Preservation and Incorporation of Valuable Endoscopic Innovations) on real-time endoscopic assessment of the histology of diminutive colorectal polyps. Gastrointest Endosc 2011; 73: $419-422$
9 Dashwood RH. Early detection and prevention of colorectal cancer (review). Oncol Rep 1999; 6: 277-281

10 Rex DK. Narrow-band imaging without optical magnification for histologic analysis of colorectal polyps. Gastroenterology 2009; 136: $1174-$ 1181

11 Ladabaum U, Fioritto A, Mitani A et al. Real-time optical biopsy of colon polyps with narrow band imaging in community practice does not yet meet key thresholds for clinical decisions. Gastroenterology 2013; 144: 81 -91

12 Hewett DG, Kaltenbach T, Sano Y et al. Validation of a simple classification system for endoscopic diagnosis of small colorectal polyps using narrow-band imaging. Gastroenterology 2012; 143: 599-607.e1

13 Hayashi $N$, Tanaka S, Hewett DG et al. Endoscopic prediction of deep submucosal invasive carcinoma: validation of the narrow-band imaging international colorectal endoscopic (NICE) classification. Gastrointestinal Endoscopy 2013; 78: 625-632

14 Rastogi A, Keighley J, Singh $V$ et al. High accuracy of narrow band imaging without magnification for the real-time characterization of polyp histology and its comparison with high-definition white light colonoscopy: a prospective study. Am J Gastroenterology 2009; 104: $2422-$ 2430

15 Ignjatovic A, East JE, Suzuki N et al. Optical diagnosis of small colorectal polyps at routine colonoscopy (Detect InSpect ChAracterise Resect and Discard; DISCARD trial): a prospective cohort study. Lancet Oncol 2009; $10: 1171-1178$

16 RIVM. Protocol for the authorization and auditing of colonoscopy centres and endoscopists. 2012: 1 -68. Available from: http://www.rivm. nl/Bibliotheek/Professioneel_Praktisch/Protocollen/Preventie_Ziekte_Zorg/Darmkanker/Protocol_voor_de_toelating_en_auditing_van_coloscopiecentra_en_endoscopisten

17 Butterly LF, Chase MP, Pohl $H$ et al. Prevalence of clinically important histology in small adenomas. Clinical gastroenterol hepatol 2006; 4: $343-348$

18 Wanders LK, East JE, Uitentuis SE et al. Diagnostic performance of narrowed spectrum endoscopy, autofluorescence imaging, and confocal laser endomicroscopy for optical diagnosis of colonic polyps: a metaanalysis. Lancet Oncol 2013; 14: 1337-1347

19 Tanaka S, Sano Y. Aim to unify the narrow band imaging (NBI) magnifying classification for colorectal tumors: current status in Japan from a summary of the consensus symposium in the 79th Annual Meeting of the Japan Gastroenterological Endoscopy Society. Dig Endosc 2011; 23: $131-139$ 